\title{
Article \\ Bacteroides fragilis Enterotoxin Upregulates Matrix Metalloproteinase-7 Expression through MAPK and AP-1 Activation in Intestinal Epithelial Cells, Leading to Syndecan-2 Release
}

\author{
Jong Ik Jeon, Keun Hwa Lee *(i) and Jung Mogg Kim * (1) \\ Department of Microbiology and Institute for Rheumatology Research, Hanyang University College of Medicine, \\ Seoul 04763, Korea; siela@hanmail.net \\ * Correspondence: yomust7@gmail.com (K.H.L.); jungmogg@hanyang.ac.kr (J.M.K.); \\ Tel.: +82-2-2220-0642 (K.H.L.); +82-2-2220-0645 (J.M.K.); \\ Fax: +82-2-2282-0645 (K.H.L.); +82-2-2282-0645 (J.M.K.)
}

check for updates

Citation: Jeon, J.I.; Lee, K.H.; Kim, J.M. Bacteroides fragilis Enterotoxin Upregulates Matrix

Metalloproteinase-7 Expression through MAPK and AP-1 Activation in Intestinal Epithelial Cells, Leading to Syndecan-2 Release. Int. J. Mol. Sci. 2021, 22, 11817. https://doi.org/ 10.3390/ijms222111817

Academic Editors: Salvatore Papa and Concetta Bubici

Received: 3 October 2021

Accepted: 28 October 2021

Published: 30 October 2021

Publisher's Note: MDPI stays neutral with regard to jurisdictional claims in published maps and institutional affiliations.

Copyright: (c) 2021 by the authors. Licensee MDPI, Basel, Switzerland. This article is an open access article distributed under the terms and conditions of the Creative Commons Attribution (CC BY) license (https:// creativecommons.org/licenses/by/ $4.0 /)$.

\begin{abstract}
Bacteroides fragilis enterotoxin (BFT) produced by enterotoxigenic $B$. fragilis (ETBF) causes colonic inflammation. BFT initially contacts intestinal epithelial cells (IECs) and affects the intestinal barrier. Although molecular components of the gut epithelial barrier such as metalloproteinase-7 (MMP-7) and syndecan-2 are known to be associated with inflammation, little has been reported about MMP-7 expression and syndecan-2 shedding in response to ETBF infection. This study explores the role of BFT in MMP-7 induction and syndecan-2 release in IECs. Stimulating IECs with BFT led to the induction of MMP-7 and the activation of transcription factors such as NF- $\mathrm{kB}$ and AP-1. MMP-7 upregulation was not affected by NF- $\mathrm{B}$, but it was related to AP-1 activation. In BFT-exposed IECs, syndecan-2 release was observed in a time- and concentration-dependent manner. MMP-7 suppression was associated with a reduction in syndecan-2 release. In addition, suppression of ERK, one of the mitogen-activated protein kinases (MAPKs), inhibited AP-1 activity and MMP-7 expression. Furthermore, the suppression of AP-1 and ERK activity was related to the attenuation of syndecan-2 release. These results suggest that a signaling cascade comprising ERK and AP-1 activation in IECs is involved in MMP-7 upregulation and syndecan-2 release during exposure to BFT.
\end{abstract}

Keywords: Bacteroides fragilis; enterotoxin; IECs; MMP-7; syndecan-2

\section{Introduction}

Enterotoxin-producing Bacteroides fragilis (ETBF) causes several colonic diseases, including inflammation and cancer [1,2]. B. fragilis enterotoxin (BFT), a virulence factor of $\mathrm{ETBF}$, is responsible for that pathogenesis [1,3]. BFT secreted by ETBF contacts intestinal epithelial cells (IECs), and the subsequent effects can induce colonic inflammation and breaks in the gut barrier. Maintaining a steady status of epithelial cell-to-cell junctions requires E-cadherin and $\beta$-catenin structures in the intestinal barrier [4]. In our previous studies of ETBF infection, we demonstrated that artificially injecting BFT into the murine ileum eventually destroyed gut integrity through villous destruction, neutrophil infiltration, and mucosal congestion [5]. In addition, BFT produced by ETBF cleaves the extracellular domain of E-cadherin that is involved in preserving the integrity of IEC barriers [6]. Matrix metalloproteinase (MMP)-7 is reported to mediate the degradation of E-cadherin in proximal tubular cells, which leads to the nuclear translocation of $\beta$-catenin [7]. The nuclear translocation of $\beta$-catenin can also control MMP-7 expression in colorectal cancer tissues [8]. We recently reported that BFT induces the translocation of $\beta$-catenin into the nuclei of IECs [9]. Based on those observations, we hypothesized that BFT might influence MMP-7 expression. However, little is known about MMP-7 expression in IECs treated with BFT. 
MMPs are zinc-dependent proteinases that perform essential functions in controlling the synthesis and degradation of the basement membrane and the extracellular matrix in intestinal barriers [10]. They fulfill their functions by processing non-matrix bioactive substrates associated with membrane shedding, modifying chemokines or growth factors, and modulating the activity of other proteases $[10,11]$. Therefore, they regulate physiologic functions, including cell proliferation and differentiation, tissue homeostasis, and immunologic responses [10]. MMPs are structurally related but genetically distinct molecules that are classified into five subgroups depending on the structure and specificity of the substrate: (a) collagenases (MMP-1, MMP-8, and MMP-13), (b) gelatinases (MMP-2 and MMP-9), (c) stromelysins (MMP-3, MMP-10, and MMP-11), (d) matrilysins (MMP-7 and MMP-26), and (e) membrane-type (MMP-14, MMP-15, and MMP-16) [8,12]. Our study target, MMP-7, is found constitutively in the IECs and associated with tissue remodeling and the IEC response to infection [13]. In addition, secreted forms of MMP-7 can modify several pathophysiological functions such as tumor metastasis and inflammation [14].

Signals from transcription factors, including nuclear factor-kappaB (NF-kB) and activator protein-1 (AP-1), can control MMP-7 expression [15-18]. We already demonstrated that stimulating IECs with BFT can activate the signaling of those transcription factors [5,19-22]. However, there is no evidence that the BFT-induced signaling is associated with MMP-7 induction in IECs. In this study, we explored the regulation of MMP-7 expression in IECs exposed to BFT. We found that signaling pathways comprising ERK mitogen-activated protein kinases (MAPKs) and AP-1 were essential for MMP-7 induction following exposure to BFT. Those results were associated with the shedding of syndecan-2 in BFT-exposed IECs.

\section{Results}

\subsection{BFT Upregulates MMP-7 Expression in IECS}

Treating HCT-116 cells with BFT upregulated the expression of MMP-7 proteins (Figure 1A). In addition, CCD $841 \mathrm{CoN}$ cells (a normal colonic epithelial cell line) treated with BFT also increased their MMP-7 expression, as assessed by immunoblotting (Figure 1B). In another experiment, the levels of soluble MMP-7 were measured with an ELISA kit using conditioned medium from HCT-116 cells treated with BFT. As shown in Figure 1C, a significant increase in soluble MMP-7 was first noted $6 \mathrm{~h}$ after treatment with BFT and continued to $24 \mathrm{~h}$ post-stimulation.

\subsection{Activation of NF-kB Is Not Associated with MMP-7 Induction in IECs following BFT Stimulation}

The NF- $\mathrm{kB}$ transcription factor was activated in BFT-exposed HCT-116 cells (Figure 2A). We next used transfection models to examine whether NF- $\mathrm{kB}$ activation was linked to MMP-7 upregulation in IECs. Transfection with lentivirus-IкB $\alpha-A A$ decreased the nuclear phospho-p65 signal to the control level after BFT treatment (Figure 2B, top panels). In this experiment, transfection with lentivirus-IкB $\alpha$-AA did not significantly change the expression of MMP-7 in HCT-116 cells (Figure 2B, bottom panels). In another experiment, we used p65 siRNA to inhibit NF- $\mathrm{kB}$ activity. p65 siRNA suppressed the nuclear protein expression of phospho-p65 in BFT-treated cells (Figure 2C, top panels). However, no change in MMP-7 expression was observed between the cells transfected with p65 siRNA and untransfected cells (Figure 2C, bottom panels).

\subsection{AP-1 Is Involved in the Upregulation of MMP-7 in BFT-Stimulated IECS}

The transcription factor AP-1 was also activated in BFT-exposed HCT-116 cells (Figure 3A). Transfection with lentivirus-dn-c-jun suppressed the phospho-c-jun signal to control levels in BFT-stimulated HCT-116 cells, whereas the control GFP did not diminish (Figure 3B, top panels). In this experiment, transfection with lentivirus-dn-c-jun significantly reduced the levels of MMP-7 expression in HCT-116 cells (Figure 3B, bottom panels). We next used siRNA against c-jun to suppress AP-1 activity. As shown in the top panels of Figure 3C, transfection with siRNA against c-jun inhibited the signals of nuclear 
phospho-c-jun. In this experiment, c-jun siRNA significantly attenuated MMP-7 expression under BFT-stimulation conditions (Figure 3C, bottom panels).

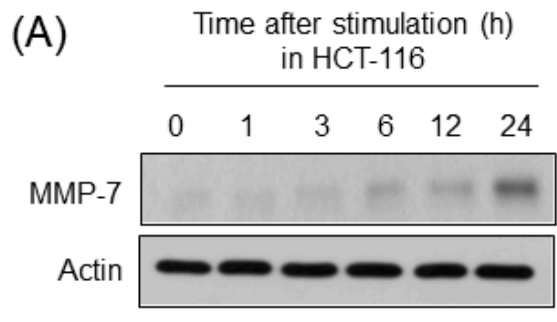

(B)

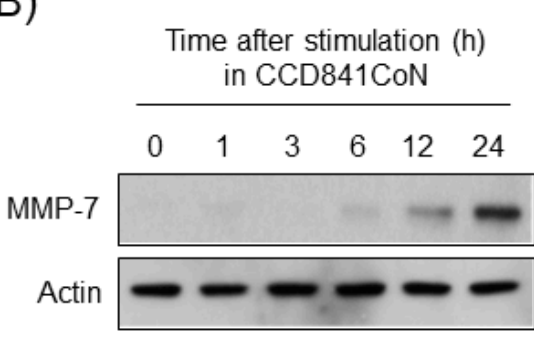

(C)

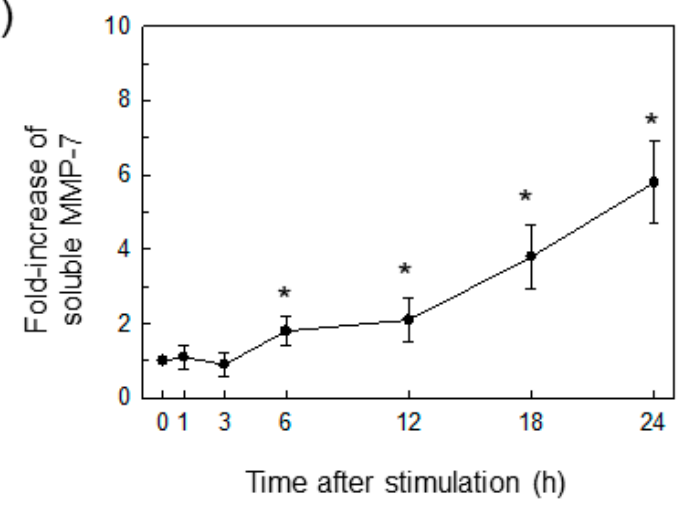

Figure 1. BFT enhances MMP-7 expression in IECs. (A,B) HCT-116 (A) and CCD 841 CoN cells (B) were treated with BFT $(300 \mathrm{ng} / \mathrm{mL}$ ) for the indicated periods. Protein expression of pro-MMP-7 and actin was evaluated by Western blotting. All images are representative of more than three independent experiments. Densitometric analysis for expressed proteins represents the relative densities of each protein compared with actin. (C) HCT-116 cells were treated with the indicated concentrations of BFT for $24 \mathrm{~h}$. Levels of soluble MMP-7 were analyzed in the conditioned media using an ELISA kit. Values are expressed as the mean $\pm \operatorname{SEM}(n=5) .{ }^{*}, p<0.05$ compared with the untreated control. 
(A)



Nuclear p-p65

Lamin B



\section{(B)}

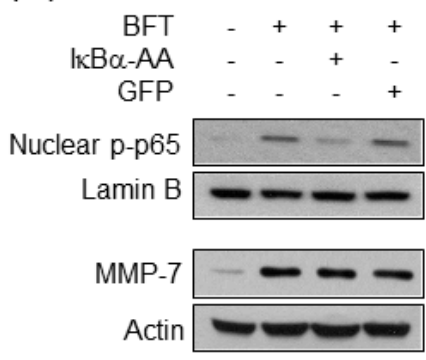

(C)

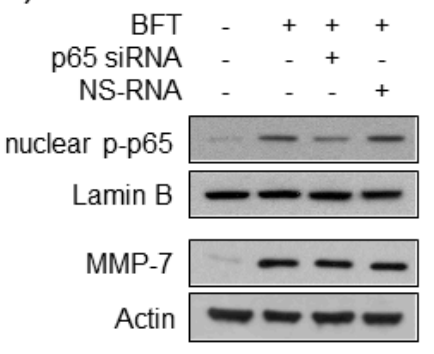

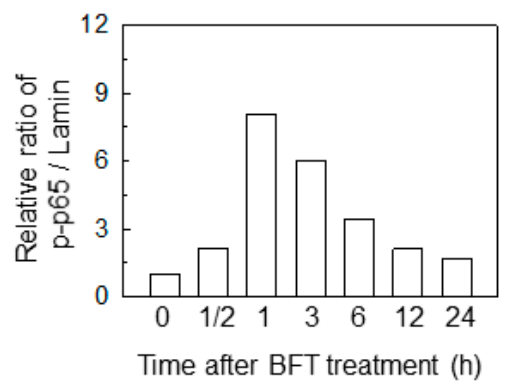
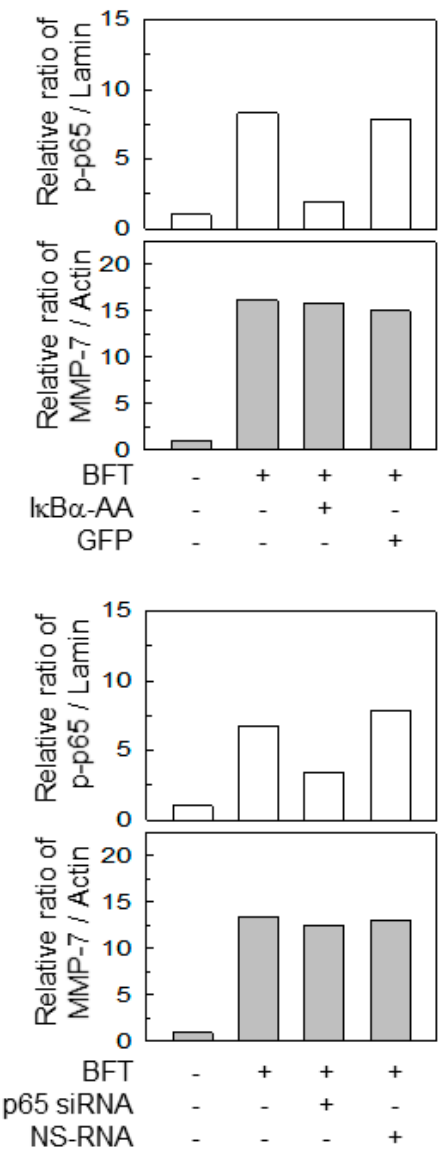

Figure 2. Effects of NF- $\kappa B$ suppression on MMP-7 expression in IECs stimulated with BFT. (A) HCT116 cells were treated with BFT at a concentration of $300 \mathrm{ng} / \mathrm{mL}$ for the indicated period. Expression of phospho-p65 and lamin B in nuclear extracts was detected by immunoblotting. (B) HCT-116

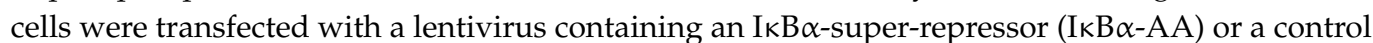
virus (GFP). Transfected cells were stimulated with BFT (300 ng/mL) for $1 \mathrm{~h}$ (phos-pho-p65) or $24 \mathrm{~h}$ (MMP-7). Expression of phospho-p65 in the nuclear factions and MMP-7 in the whole-cell lysates was assessed by immunoblotting. (C) HCT-116 cells were transfected with NF- $\mathrm{B}$ p 65 -specific siRNA or non-silencing siRNA (NS-RNA) as a control for $48 \mathrm{~h}$, after which the cells were combined with BFT (300 ng/mL) for $1 \mathrm{~h}$ (phospho-p65) or $24 \mathrm{~h}$ (MMP-7). Expression of phospho-p65 in the nuclear factions and MMP-7 in the whole-cell lysates was assessed by immunoblotting. All results shown are representative of more than three independent experiments. Densitometric analysis for expressed proteins represents the relative densities of each protein compared with actin or lamin B. 
(A)


(B)
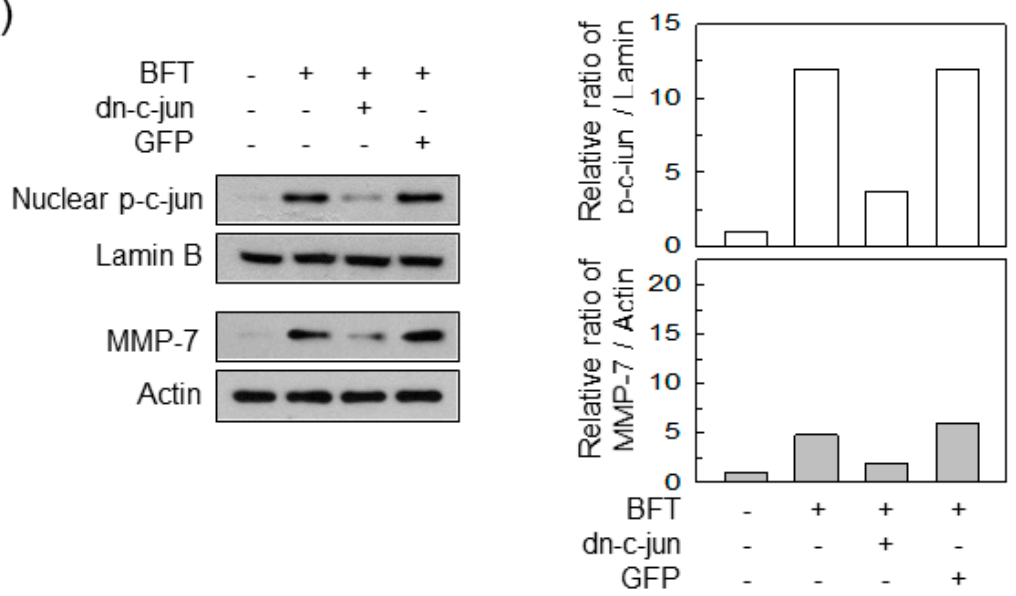

(C)
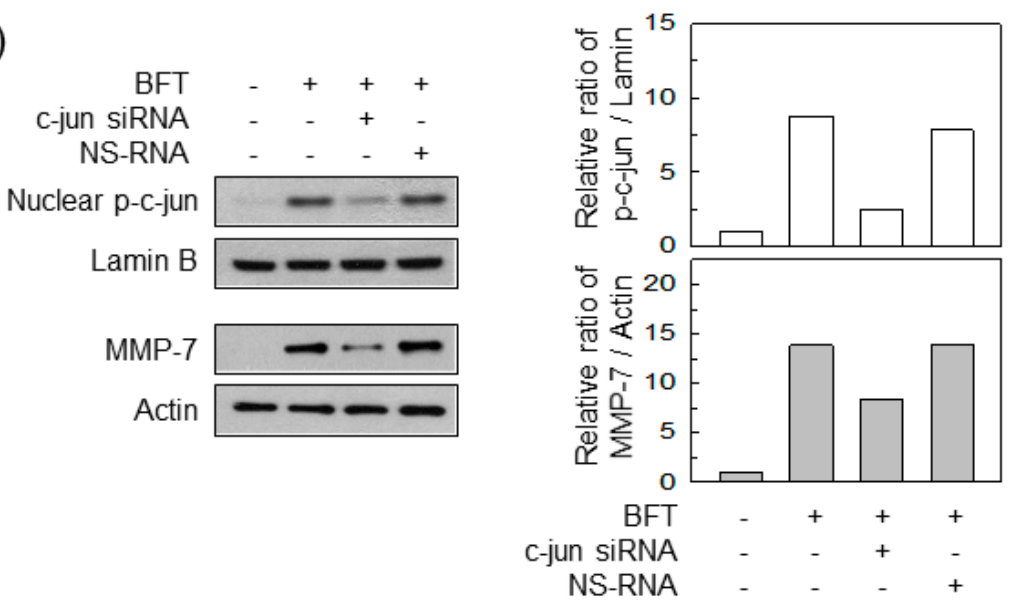

Figure 3. Effects of AP-1 suppression on MMP-7 expression in IECs stimulated with BFT. (A) HCT116 cells were treated with BFT at a concentration of $300 \mathrm{ng} / \mathrm{mL}$ for the indicated period. Nuclear protein expression of phospho-c-jun and lamin B was detected by immunoblotting. (B) HCT-116 cells were transfected with a lentivirus containing dominant-negative c-jun plasmid (dn-c-jun) or a control virus (GFP). Transfected cells were stimulated with BFT (300 ng/mL) for $1 \mathrm{~h}$ (phospho-c-jun) or $24 \mathrm{~h}$ (MMP-7). The expression of phospho-c-jun in the nuclear extracts and MMP-7 in the whole-cell lysates was assayed by immunoblotting. (C) HCT-116 cells were transfected with c-jun-specific siRNA or non-silencing siRNA (NS-RNA) as a control for $48 \mathrm{~h}$, after which the cells were combined with BFT (300 ng/mL) for $1 \mathrm{~h}$. Expression of phospho-c-jun in the nuclear factions and MMP-7 in the whole-cell lysates was assessed by immunoblotting. All results shown are representative of more than three independent experiments. Densitometric analysis for expressed proteins represents the relative densities of each protein compared with actin or lamin $\mathrm{B}$. 


\subsection{ERK Is Involved in the Upregulation of MMP-7 in BFT-Stimulated IECS}

BFT stimulation activated the phosphorylated forms of MAPK proteins such as ERK1/2, p38, and JNK in HCT-116 cells (Figure 4A). CCD 841 CoN cells treated with BFT also increased their production of the phosphorylated form of each MAPK (Figure 4B). To evaluate the effects of MAPK inhibition on the MMP-7 induction in BFT-treated cells, we used chemical kinase inhibitors as previously described [23,24]. Under BFT-stimulated conditions, MMP-7 expression was first inhibited significantly at $10 \mu \mathrm{M}$ concentration of PD98059 (ERK inhibitor). In contrast, SB203580 (p38 inhibitor) and SP600125 (JNK inhibitor) first significantly inhibited MMP-7 expression at a concentration of $50 \mu \mathrm{M}$ (Figure 4C).



(B) Time after stimulation (mim)
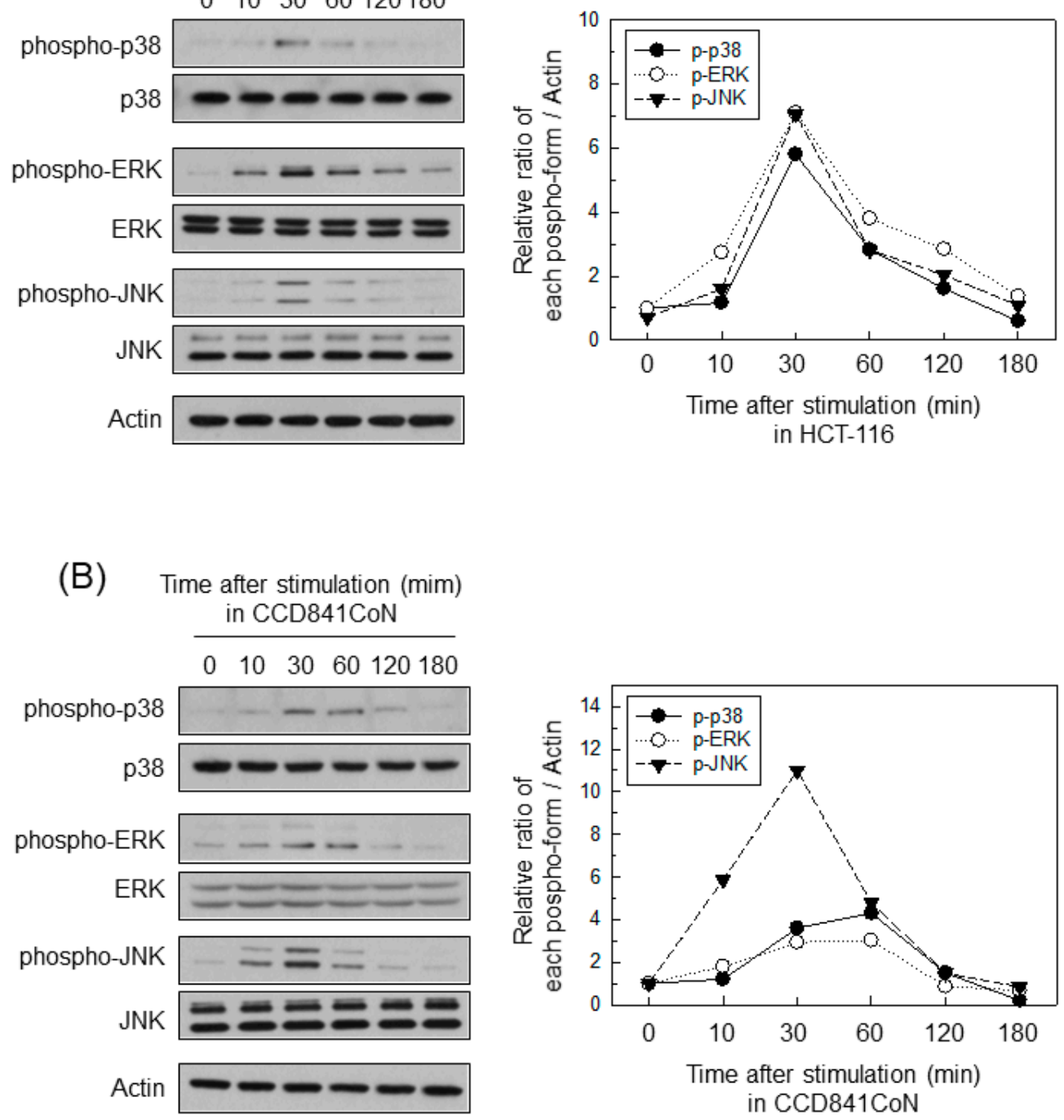

Figure 4. Cont. 
(C)

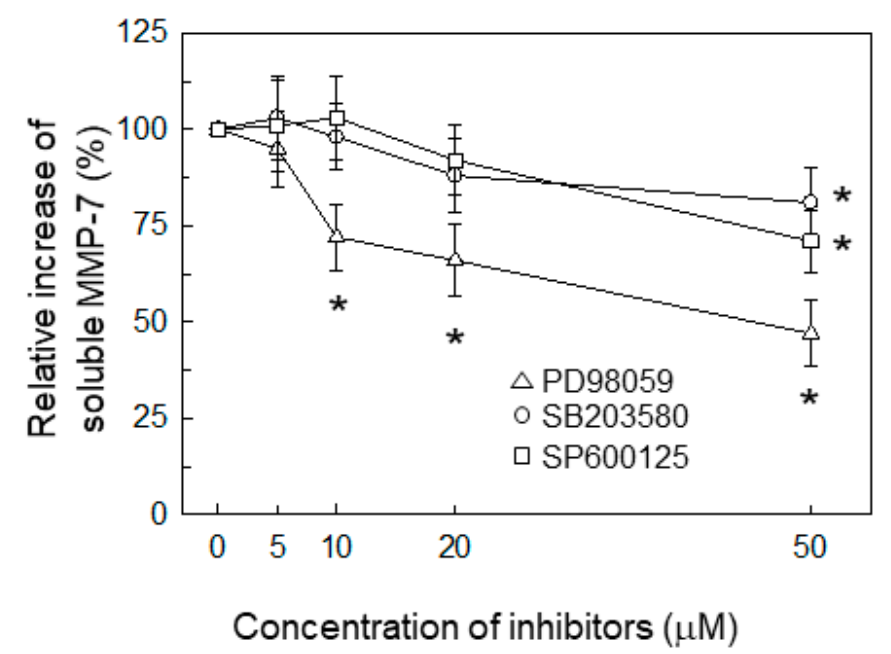

Figure 4. Effects of MAPK chemical inhibitors on MMP-7 expression in IECs stimulated with BFT. $(\mathbf{A}, \mathbf{B})$ CCD $841 \mathrm{CoN}(\mathbf{A})$ and HCT-116 cells $(\mathbf{B})$ were treated with BFT at a concentration of $300 \mathrm{ng} / \mathrm{mL}$ for the indicated period. Protein expression of ERK1/2, phospho-ERK1/2, p38, phospho-p38, JNK and phospho-JNK was detected by immunoblotting. All pictures are representative of more than three independent experiments. Densitometric analysis for expressed proteins of each phospho-form represents the relative densities of each protein compared with actin. (C) CCD 841 CoN cells were preincubated with SB203580, SP600125, or PD98059 for $30 \mathrm{~min}$. BFT (300 $\mathrm{ng} / \mathrm{mL}$ ) was then added to each group for $24 \mathrm{~h}$. Levels of soluble MMP-7 were evaluated by ELISA. Data are expressed as a mean $\%$ increase relative to unstimulated controls $\pm \operatorname{SEM}(n=5) .{ }^{*}, p<0.05$ compared with BFT alone.

We next performed experiments using lentiviral systems containing dominant-negative plasmids to confirm those findings. Transfection with lentiviruses containing a dominantnegative Erk2 plasmid (lentivirus-dn-Erk) suppressed the phosphorylation of Elk1 proteins in HCT-116 cells (Figure 5A, top panels). In this experiment, the lentivirus-dn-Erk significantly decreased MMP-7 expression following BFT stimulation (Figure 5A, bottom panels). In contrast, transfection with lentiviruses containing a dominant-negative p38 plasmid (lentivirus-dn-p38) did not significantly change the expression of MMP-7 in BFT-stimulated HCT-116 cells (Figure 5B). Lentiviral infection with a dominant-negative JNK1 plasmid (lentivirus-dn-JNK) did not affect MMP-7 expression, either (Figure 5C). To further investigate ERK-induced AP-1 activation, we used ELISA kits to measure AP-activity. Infection with lentivirus-dn-Erk reduced AP-1 activity in cells treated with BFT (Figure 5D). Thus, exposing IECs to BFT might trigger a signaling pathway comprising ERK, AP-1, and MMP-7 induction.

\subsection{BFT-Induced MMP-7 Upregulation Is Associated with Syndecan-2 Release in IECs}

Because the extracellular domain of syndecan-2 is cleaved by MMP-7 in colon cancer cells $[16,25]$, it is likely that MMP-7 is involved in syndecan-2 shedding when BFT contacts IECs. To investigate that hypothesis, we first examined whether BFT could induce syndecan-2 release in IECs. As shown in the top panels of Figure 6A, treating HCT-116 cells with BFT enhanced the levels of soluble syndecan-2. CCD 841 CoN cells exposed to BFT also increased soluble syndecan-2 levels in slot blot and conditioned culture supernatant assessments (Figure 6A, bottom panel). In the following experiment, the concentration of soluble syndecan-2 was measured using an ELISA kit with conditioned culture supernatants from HCT-116 cells treated with BFT. As shown in Figure 6B, a significant increase in soluble syndecan- 2 was first noted $12 \mathrm{~h}$ following BFT exposure and continued to $24 \mathrm{~h}$ post-stimulation. The increase in soluble syndecan-2 depended on the concentration of BFT used for stimulation (Figure 6C). 

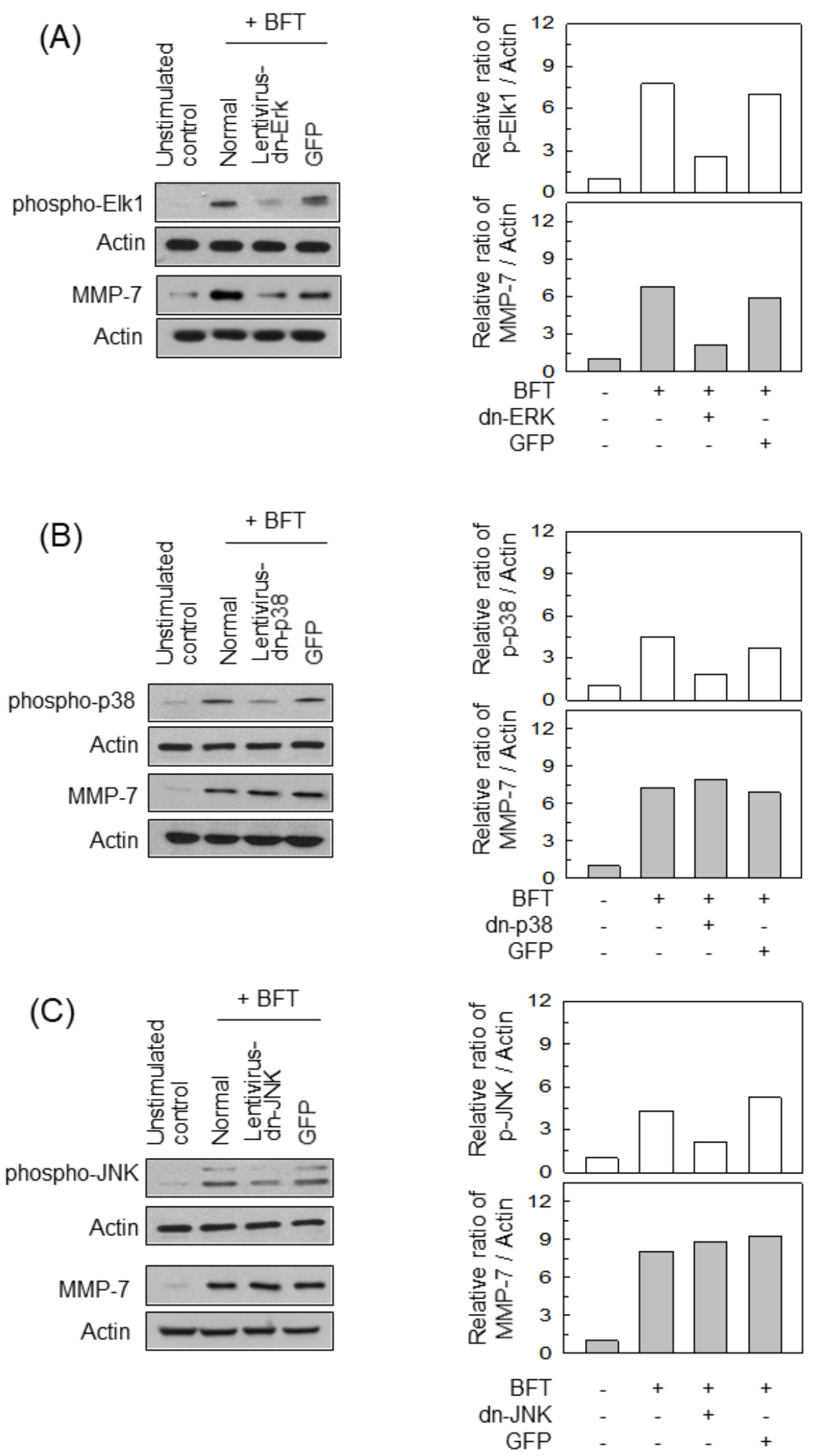

Figure 5. Cont. 
(D)

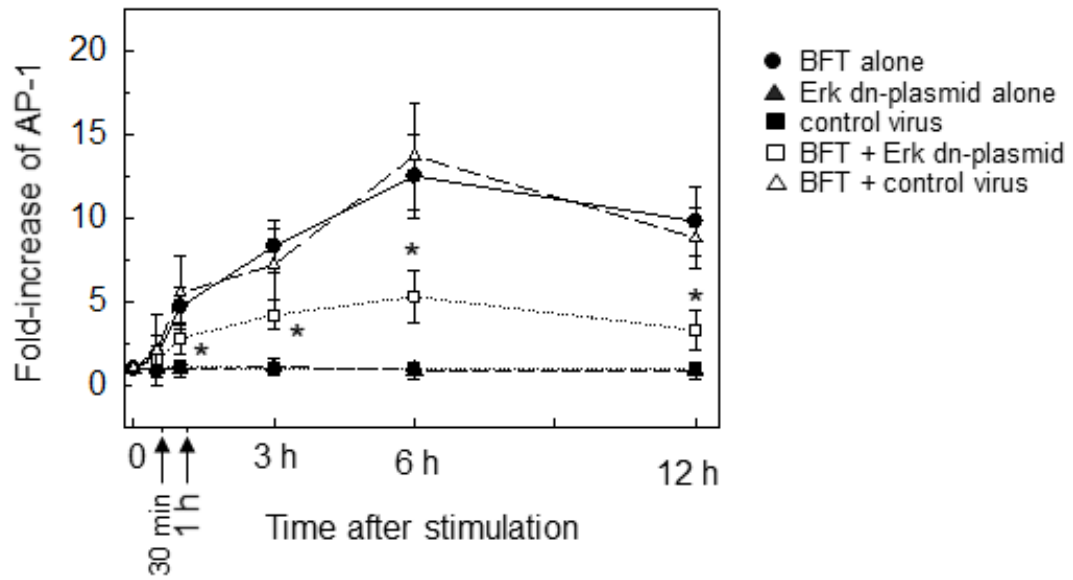

Figure 5. Effects of MAPK suppression on MMP-7 expression in IECs stimulated with BFT. (A) HCT116 cells were transfected with lentiviruses containing a dominant-negative Erk (dn-Erk) or a control plasmid (GFP). Cells were treated with BFT at a concentration of $300 \mathrm{ng} / \mathrm{mL}$ for $30 \mathrm{~min}$ (top panels, phospho-Elk1) and $24 \mathrm{~h}$ (bottom panels, MMP-7). (B) HCT-116 cells were transfected with lentiviruses containing a dominant-negative p38 or the control plasmid. The culture conditions were identical to those in (A). The top panels show phospho-38, and the bottom panels show MMP-7 signals. (C) HCT-116 cells were transfected with lentiviruses containing a dominant-negative JNK or the control plasmid. The culture conditions were identical to those in (A). The top panels show phosphoJNK, and the bottom panels show MMP-7. Protein expression was determined by Western blotting. All images in (A-C) are representative of more than three independent experiments. Densitometric analysis for expressed proteins represents the relative densities of each protein compared with actin or lamin B. (D) Each lentivirus-infected cell was treated with BFT (300 ng/mL), and then AP-1 activity was determined by ELISA. Data are expressed as the mean fold induction $\pm \operatorname{SEM}(n=5) .{ }^{*}, p<0.05$ compared with BFT alone.

We next examined whether BFT-induced MMP-7 upregulation is related to syndecan-2 release in IECs. A transfection model with siRNA was used to suppress MMP-7 signals in BFT-exposed cells. The experiment using whole-cell lysate obtained from MMP-7 siRNAtransfected cells showed the apparent suppression of MMP-7 signals under BFT-stimulated conditions (Figure 7A, top panels). As assessed by slot blotting and the conditioned culture supernatant, MMP-7 siRNA transfection led to a significant reduction in soluble syndecan-2 compared with untransfected cells stimulated with BFT, and transfection with NS-RNA as a control had no significant effect (Figure 7A, bottom panels). In another experiment, BFT significantly increased both soluble MMP-7 and soluble syndecan-2 in the conditioned media. In that experiment, transfection with MMP-7 siRNA significantly decreased the levels of soluble MMP-7 and soluble syndecan-2 (Figure 7B). In the next experiment, CCD 841 CoN cells were preincubated with GM6001 (10 $\mu \mathrm{M})$, a broad-spectrum MMP inhibitor, and then treated with BFT. As shown in Figure 7C, GM6001 significantly suppressed syndecan-2 release compared with untreated cells. Those results might allow the establishment of a theory of MMP-7-dependent induction of syndecan-2 release in IECs exposed to BFT. 

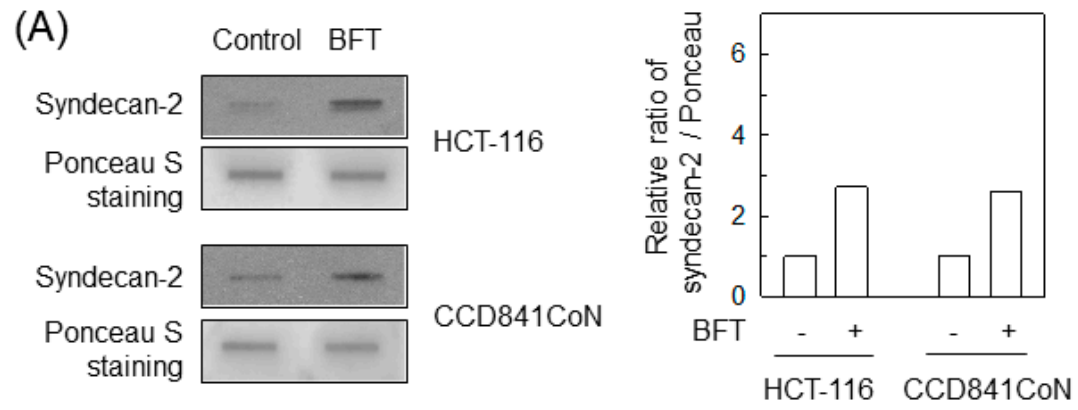

(B)



(C)

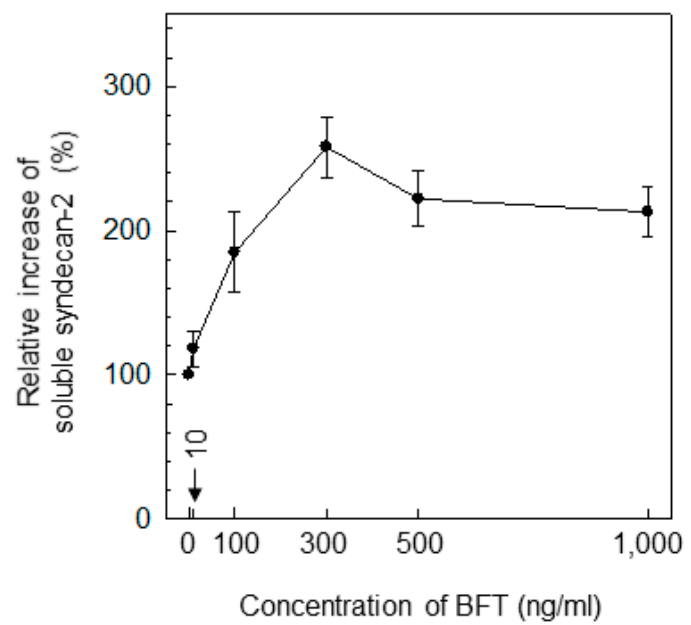

Figure 6. BFT promotes release of syndecan-2 in IECs. (A) HCT-116 (top panels) and CCD 841 CoN cells (bottom panels) were treated with BFT $(300 \mathrm{ng} / \mathrm{mL}$ ) for $24 \mathrm{~h}$, and then conditioned media were collected and analyzed by slot blotting with an anti-syndecan- 2 antibody. Ponceau $S$ staining was used to check for equal protein loading. All images are representative of more than three independent experiments. Densitometric analysis for expressed proteins represents the relative densities of each protein compared with Ponceau S. (B) HCT-116 cells were treated with BFT $(300 \mathrm{ng} / \mathrm{mL})$ for the indicated periods. Quantitative analysis of syndecan-2 released in conditioned media was performed using an ELISA kit. ${ }^{*} p<0.05$ compared with untreated control. (C) HCT-116 cells were treated with the indicated concentrations of BFT for $24 \mathrm{~h}$. Levels of soluble syndecan-2 were analyzed in the conditioned media by an ELISA kit. Values are expressed as the mean $\pm \operatorname{SEM}(n=5) .{ }^{*}, p<0.05$ compared with the untreated control. 

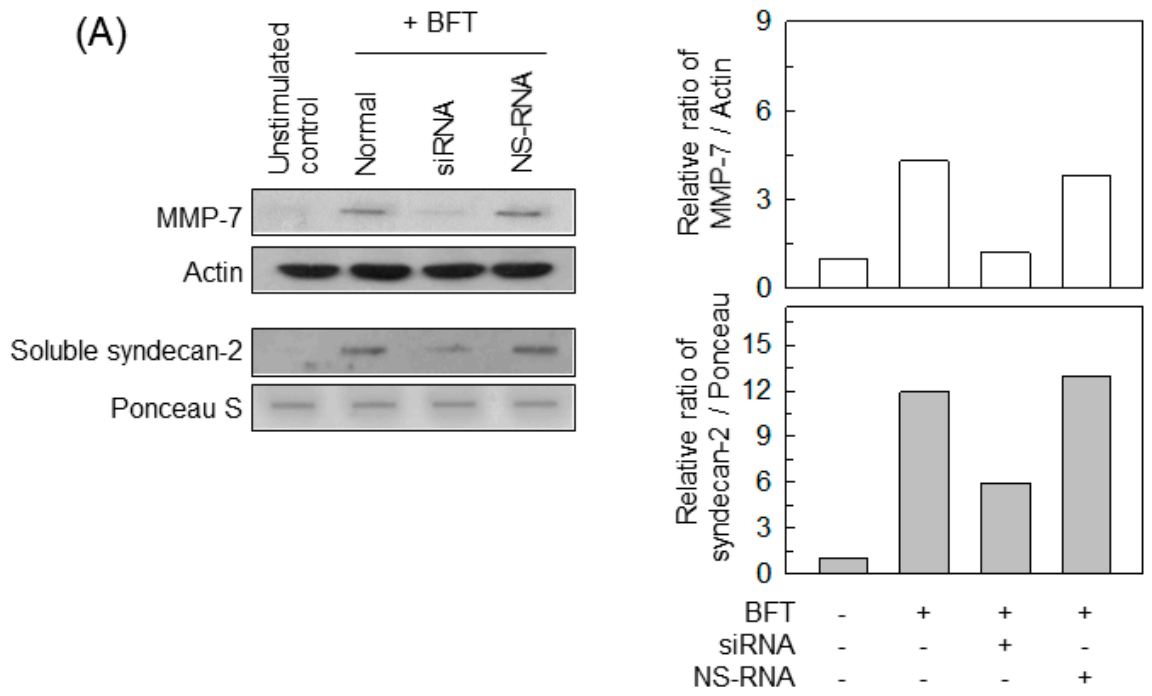

(B)


Figure 7. Effects of MMP-7 suppression on syndecan-2 release in IECs stimulated with BFT. (A) HCT116 cells were transfected with either MMP-7 siRNA or non-silencing siRNA (NS-RNA). Cells were treated with BFT at a concentration of $300 \mathrm{ng} / \mathrm{mL}$ for $24 \mathrm{~h}$. Protein expression of MMP-7 and actin was detected by Western blotting (top panels). The soluble form of syndecan- 2 was evaluated using conditioned media and slot blotting with each antibody. Protein loading in blots was determined by Ponceau S staining (bottom panels). All images are representative of more than three independent experiments. Densitometric analysis for expressed proteins represents the relative densities of each protein compared with actin or Ponceau S. (B) HCT-116 cells were treated with the indicated concentrations of BFT for $24 \mathrm{~h}$. Levels of soluble MMP-7 and syndecan-2 in the conditioned media were analyzed using ELISA kits. Values are expressed as the mean $\pm \operatorname{SEM}(n=5)$. (C) CCD $841 \mathrm{CoN}$ cells were treated with BFT (300 ng/mL) in the presence and absence of GM6001 $(10 \mu \mathrm{M})$ for $24 \mathrm{~h}$. Levels of soluble syndecan-2 were analyzed in the conditioned media using ELISA kits. Values are expressed as the mean $\pm \operatorname{SEM}(n=5) .{ }^{*}, p<0.05$ compared with the untreated control.

\subsection{AP-1 Signaling Is Involved in Syndecan-2 Release in IECs Stimulated with BFT}

We used a lentivirus-transfection system to examine the involvement of transcriptional factors in syndecan-2 shedding. In the experiment that used lentivirus-IкB $\alpha$-AA transfection (Figure 2B), suppressing NF- $\mathrm{kB}$ activity did not affect soluble MMP-7 or syndecan-2 upon BFT exposure (Figure 8A). In contrast, transfection with lentivirus-dn-c-jun significantly reduced the levels of soluble MMP-7 and syndecan-2 in HCT-116 cells (Figure 8B). Primary intestinal epithelial CCD 841 CoN cells were pre-incubated with Bay 11-7082 
(NF-KB inhibitor) or SR11302 (AP-1 inhibitor) for $30 \mathrm{~min}$, and then stimulated with BFT to confirm those results. As shown in Figure 8C, pretreating CCD 841 CoN cells with SR11302 resulted in a significant decrease in soluble MMP-7 and soluble syndecan-2 compared with treatment with BFT alone. However, pretreatment with Bay 11-7082 did not significantly change the BFT-induced levels of soluble MMP-7 and syndecan-2.

(A)

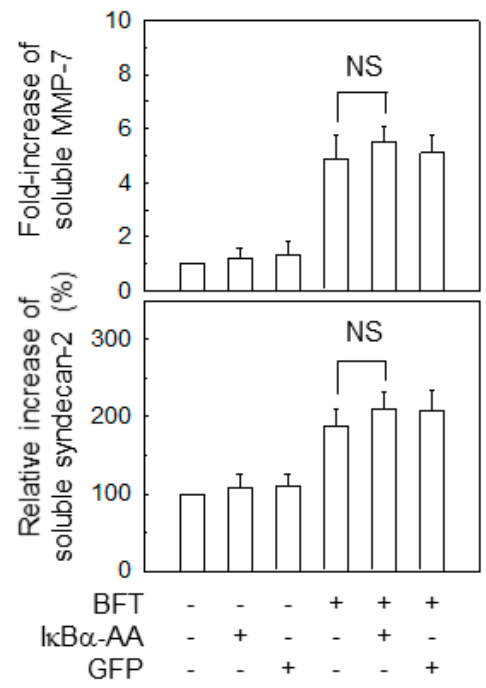

(B)

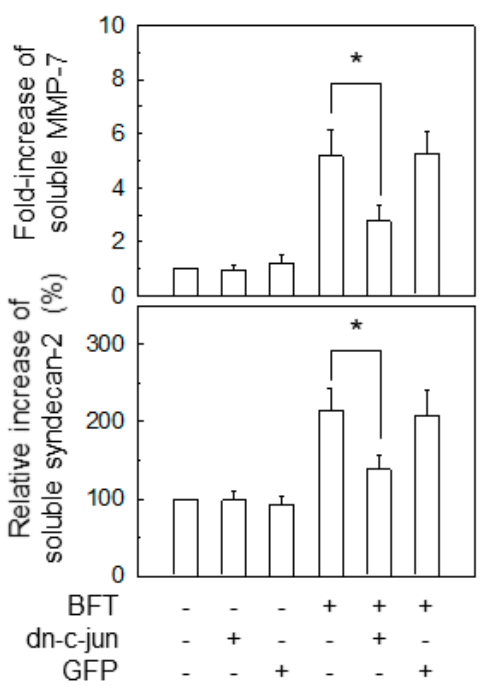

(C)

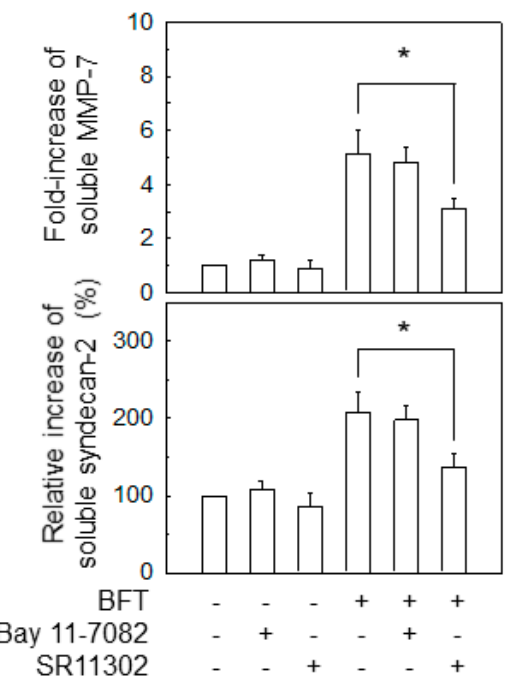

Figure 8. Effects of transcription factor suppression on syndecan-2 shedding in IECs stimulated with BFT. (A) The culture conditions for the HCT-116 cells were identical to those in Figure 5A-C using those respective lentiviral vectors. Cells were treated with BFT at a concentration of $300 \mathrm{ng} / \mathrm{mL}$ for $24 \mathrm{~h}$. Levels of soluble MMP-7 and syndecan- 2 in the conditioned media were analyzed using an ELISA kit. Values are expressed as the mean \pm SEM $(n=5)$. (B) HCT-116 cells were transfected with dn-c-jun or GFP, as described in Figure 3B. Cells were treated with BFT at a concentration of 300 $\mathrm{ng} / \mathrm{mL}$ for $24 \mathrm{~h}$. Levels of soluble MMP-7 and syndecan-2 in the conditioned media were analyzed using an ELISA kit. Values are expressed as the mean $\pm \operatorname{SEM}(n=5) .{ }^{*} p<0.05$ compared with the untreated control. (C) CCD 841 CoN cells were preincubated with Bay 11-7082 $(50 \mu \mathrm{M})$ or SR11302 $(10 \mu \mathrm{M})$ for $30 \mathrm{~min}$, followed by stimulation with BFT $(300 \mathrm{ng} / \mathrm{mL})$ for an additional $24 \mathrm{~h}$. Levels of soluble MMP-7 and syndecan- 2 in conditioned media were measured using ELISA (mean $\pm \mathrm{SEM}$, $n=5) .{ }^{*} p<0.05$ compared with BFT alone. NS, statistically non-significant. 


\subsection{MMP-7-Associated ERK Activation Is Essential for Syndecan-2 Release in BFT-Stimulated} IECS

In the previous experiments, BFT induced the phosphorylated forms of MAPK proteins such as p38, ERK, and JNK in HCT-116 cells (Figure 4A,B). We used lentiviral systems containing dominant-negative plasmids (Figure 5A-C) to assess the effects of MAPK signals on syndecan-2 release. Lentiviral infection with dn-Erk significantly decreased MMP-7 expression compared with the untransfected control (Figure 9A). But lentiviral infection with dn-p38 or dn-JNK produced no changes in MMP-7 expression under BFT-stimulated conditions. Similar results were obtained for soluble syndecan-2 levels in cells transfected with dn-Erk under BFT-stimulated conditions (Figure 9B).

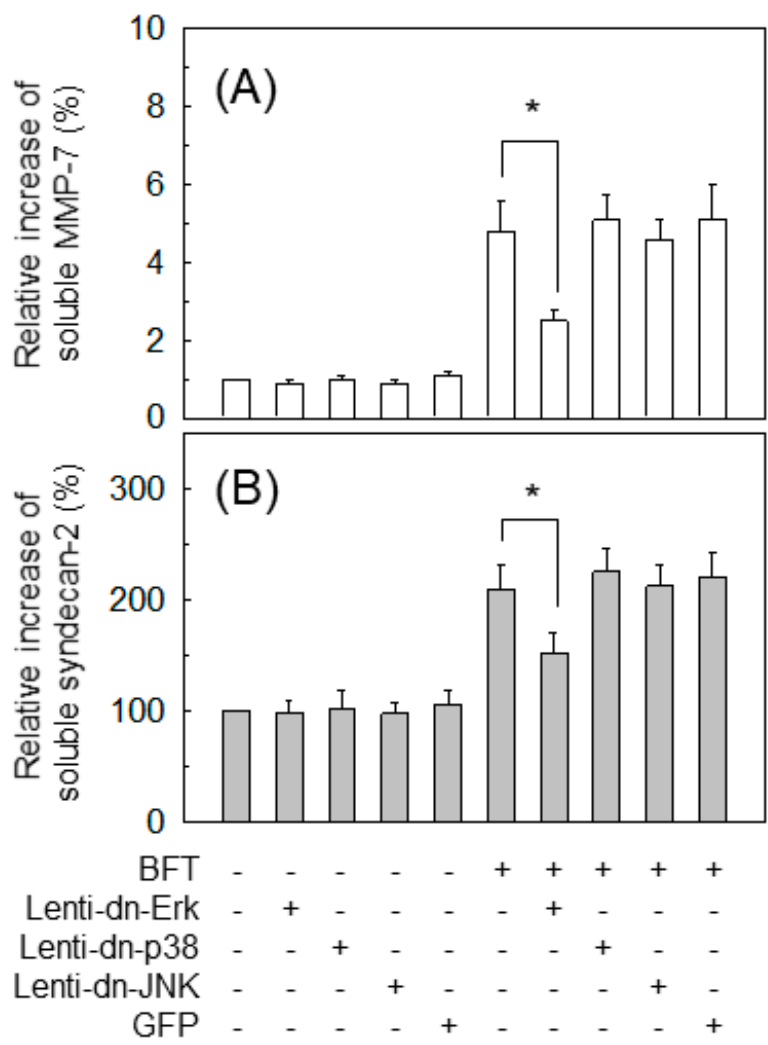

Figure 9. Effects of MAPK suppression and syndecan-2 shedding in IECs Scheme 116. cells were identical to those in Figure $5 \mathrm{~A}-\mathrm{C}$ using those respective lentiviral vectors. Cells were treated with BFT at a concentration of $300 \mathrm{ng} / \mathrm{mL}$ for $24 \mathrm{~h}$. Levels of soluble MMP-7 (A) and syndecan-2 (B) were determined using ELISA kits. Data are expressed as the mean \% increase relative to unstimulated controls $\pm \operatorname{SEM}(n=5) .{ }^{*} p<0.05$ compared with BFT alone.

\section{Discussion}

IECs exposed to BFT can express mediators, such as IL- 8 and $\beta$-catenin, and transcription factors, such as AP-1 and NF- $\mathrm{kB}$, to regulate the expression of those effector molecules $[5,9,19-22]$. Concurrently, BFT can affect several components needed to maintain the IE barrier. In this study, we showed that BFT upregulates the expression of MMP-7 and that the enhanced MMP-7 expression is associated with syndecan-2 release in IECs stimulated with BFT.

Many MMPs are synthesized and then secreted as proenzymes; MMP-7 is a solubletype MMP [26,27] that can be upregulated in IECs [28]. MMP-7 degrades a variety of matrix substrates such as elastin, gelatin, and proteoglycans. Because secreted MMP-7 might play a role in the pathogenesis of early-stage colon tumors [28], we measured its form using an ELISA kit and conditioned medium from BFT-treated cells. The cellular forms of MMP-7 
were also measured using Western blotting and cell lysates in this study. Our results show that BFT can increase both the cellular and secreted forms of MMP-7 in IECs.

Which transcription factor is responsible for MMP-7 induction is controversial. For example, isoproterenol might induce AP-1-mediated MMP-7 expression in gastric cancer cells [18], and hydrogen peroxide caused the expression of MMP-7 molecules in SW-620 human colon cancer cells via an AP-1 signaling pathway [15]. In contrast, IL-1 $\alpha$ - or TNF$\alpha$-treated IECs increased their expression of MMP-7 proteins via an NF- $\mathrm{kB}$ activation pathway $[16,17]$. In this study, exposing HCT-116 cells to BFT increased MMP-7 protein expression, and BFT-activated AP-1 signaling was involved in MMP-7 upregulation. Based on those findings, we investigated the upstream signaling associated with BFT-induced MMP-7 upregulation.

MAPK signaling is known to be an essential piece underlying the expression of several target proteins, including MMP-7 and syndecan-2. Several reports have demonstrated MAPK signaling-associated MMP-7 expression. For example, animal experiments showed that treating mice with JNK- or ERK-specific inhibitors decreased MMP-7 expression in tumor tissue, suggesting that MMP-7 induction occurs via the activation of JNK and ERK [29]. In addition, human peritoneal mesothelial cells express MMP-7 molecules via ERK activation [30]. Stimulating HT-29 cells with IL-1 $\alpha$ enhanced their MMP-7 protein secretion via activation of phospho-ERK and phospho-p38 MAPK molecules [16]. In this study, the suppression of ERK molecules suppressed both the AP-1 signal and MMP-7 expression in primary intestinal epithelial CCD $841 \mathrm{CoN}$ and HCT-116 cells treated with BFT. In contrast, inhibiting p38 or JNK activity did not influence the MMP-7 expression in IECs stimulated with BFT. Therefore, the mechanisms of ERK-associated MMP-7 induction and AP-1 activation in IECs might be stimulator-specific and seem to depend on the type of IECs.

A previous study reported that BFT could not activate the MMP-7 signaling pathway because no active form of the MMP-7 molecules was observed in Western blot assays of control or BFT-stimulated HT29/C1 cells [31]. Nevertheless, we found that MMP-7 molecules, one of the constitutive components of IECs, were upregulated in IECs exposed to BFT and that enhanced MMP-7 expression was related to syndecan-2 release. HT-29 cell lines constitutively express high levels of MMP-7 proteins in the steady state. In contrast, HCT-116 cell lines express a relatively low level of MMP-7 molecules in their stable condition [4]. Based on that finding, we used HCT-116 cell lines in this study. Nevertheless, we did not experiment with immunofluorescence experiment to confirm the status of MMP-7. It seems necessary to experiment on this issue.

Syndecans are the dominant forms of surface heparan sulfate proteoglycans in eukaryotic cells. Among microbial infections, Brucella melitensis, Pseudomonas aeruginosa, Neisseria gonorrhoeae, and other bacteria such as Staphylococcus and Streptococcus species attach and invade hosts by acting together with syndecan molecules [32-35]. Syndecan-2 is known to be involved in a variety of functions such as cell proliferation, migration, and interaction between cells and intercellular substances as well as microbial interaction. For example, syndecan-2 expressed on the surface of dendritic cells binds to HIV, after which syndecan-2 facilitates viral transmission to CD4-positive T cells [36]. The syndecan-2 knock-out state diminished both phagocytic activity against apoptotic neutrophils and the ability to convert macrophages from a proinflammatory phenotype to a pro-resolution one in mesenchymal stromal cells [37]. Helicobacter pylori infection also increased the soluble level of syndecan-2 released from epithelial cells [28]. However, nothing has been reported about the role of syndecan-2 in ETBF infection until the results of this study, which is the first report to elucidate the role of syndecan-2 in ETBF infection.

We found that PD98059 (ERK inhibitor) was superior to both SB203580 and SP600125 in diminishing MMP-7 upregulation and syndecan-2 release. We confirmed those findings by using a lentivirus-based knockdown strategy. Considering that the extracellular domain of shed syndecan-2 plays an essential role in the pro-MMP-7 activation process in IECs [38], the syndecan- 2 release induced by BFT could be involved in the pro-MMP-7 activation 
process in IECs. Further exploration is needed to clarify the roles played by the syndecan-2 released in ETBF infection.

Based on the present findings, we hypothesize that BFT activates a signaling cascade comprising ERK and AP-1 activation that is related to MMP-7 upregulation and syndecan-2 release in IECs. Our proposal could be a fruitful avenue for future investigation of ETBF infection. Nevertheless, this study has several limitations. We applied a pharmacological dose of BFT to promote MMP-7 upregulation and the syndecan-2 release. In addition, we did not examine whether the released syndecan-2 controlled MMP-7 upregulation or the pro-MMP-7 activation process in IECs stimulated with BFT. Future exploration is needed to clarify whether ETBF infection affects MMP-7 expression and syndecan-2 release in vivo and whether the released syndecan- 2 regulates the pro-MMP-7 activation process in BFT-exposed IECs. We did not perform cell migration analysis to evaluate the effect of MMP-7 production. Therefore, it is necessary for experiments to study whether MMP7 can promote cell migration using wound-healing assays and Transwell migration and invasion assays. In conclusion, MMP-7 upregulation in BFT-exposed IECs was closely related to syndecan-2 release via the BFT-induced activation of AP-1 and ERK signals.

\section{Materials and Methods}

\subsection{Reagents}

We used the following reagents in this study: antibiotics (mixture of $100 \mu \mathrm{g} / \mathrm{mL}$ of streptomycin and 100 units $/ \mathrm{mL}$ of penicillin), Trizol, $\mathrm{Ca}^{2+}$ - and $\mathrm{Mg}^{2+}$-free Hank's balanced salt solution (GIBCO BRL, Gaithersburg, MD, USA); Eagle's minimum essential medium (EMEM), McCoy's 5a medium, and fetal bovine serum (FBS) (American Type Culture Collection (ATCC), Manassas, VA, USA); Bay 11-7085, SB203580, PD98059, and SP600125 (Calbiochem, La Jolla, CA, USA); GM6001 and Ponceau S (Sigma-Aldrich, St. Louis, MO, USA); and SR11302 (MedChemExpress, Monmouth Junction, NJ, USA).

The following antibodies were used in this study: rabbit monoclonal antibodies (mAbs) against phospho-IкB $\alpha$ and rabbit polyclonal Abs against phospho-p65, phospho-cjun, pan-extracellular signal-regulated kinase 1/2 (ERK1/2, p44/p42), phospho-ERK1/2, pan-p38, phospho-p38, pan-JNK (p54/p46), and phospho-JNK (Cell Signaling Technology, Inc., Beverly, MA, USA); mouse mAb against human MMP-7 (R\&D Systems, Minneapolis, MN, USA); rabbit polyclonal Ab against human syndecan-2 (Thermo Fisher Scientific, Waltham, MA, USA); and mouse mAbs against actin and lamin B, goat anti-mouse, and anti-rabbit secondary Abs conjugated to horseradish peroxidase (Santa Cruz Biotechnology, Inc., Santa Cruz, CA, USA).

\subsection{Cell Culture Conditions and Purification of BFT}

Cell culture conditions were identical to those reported in our previous studies $[9,22,39]$. The human colonic epithelial HCT-116 cell line (ATCC CCL 247) was cultured in McCoy's 5a medium complemented with 10\% FBS and antibiotics. Normal colonic epithelial CCD 841 CoN cells (ATCC CRL-1790) were cultured with EMEM with $10 \%$ FBS and $1 \mathrm{mM}$ sodium pyruvate $[9,22]$. BFT was purified from culture supernatants of a toxigenic $B$. fragilis strain (ATCC 43858) using protocols detailed in our previous reports [9,19-22,39].

\subsection{Transfection Assay}

Lentiviral systems containing mammalian expression vectors were used to block NF$\mathrm{kB}, \mathrm{AP}-1$, or MAPK activation, as described previously [9,21,22]. Lentiviral vectors and effective viruses were supported by BioCore at the Institute of Biomedical Science (Seoul, Korea). Experiments related to transfection were performed according to the relevant manufacturer instructions $[9,21,22]$.

In this study, we used small interfering RNA (siRNA) against MMP-7, NF-kB p65, c-jun and a non-silencing siRNA (NS-RNA) as the negative control (Santa Cruz Biotechnology, Inc.). Transfected cells were incubated for $48 \mathrm{~h}$ before BFT treatment. Transfection experiments were performed according to a protocol described previously $[9,21,22]$. 


\subsection{Immunoblots and ELISA}

Expressed proteins were detected using immunoblot analyses as described previously $[9,21,22]$. An amount of 15 to $50 \mu \mathrm{g}$ of protein per lane were size-fractionated on a polyacrylamide minigel (Mini-PROTEIN II, Bio-Rad) and transferred to a nitrocellulose membrane $(0.1-\mu \mathrm{m}$ pore size; MilliporeSigma, Burlington, MA, USA) via electrophoretic transfer. Secondary Abs conjugated to horseradish peroxidase were reacted with the target proteins bound with the primary $\mathrm{Ab}$. The reaction signals were detected using a West- $\mathrm{Q}$ Chemiluminescent Substrate Kit Plus (GenDEPOT, Katy, TX, USA) and X-ray film exposure.

For slot blotting, the culture supernatants were slot-blotted to a PVDF membrane (MilliporeSigma) using a Bio-Dot SF microfiltration apparatus (Bio-Rad, Hercules, CA, USA). Equal amounts of protein were loaded onto the slot blots. Before blotting, the membrane was stained with Ponceau S. The slot blotting and immunoreaction with the anti-syndecan-2 $\mathrm{Ab}$ were performed according to a previously described method [16]. The reaction signals were detected using a West-Q Chemiluminescent Substrate Kit Plus (GenDEPOT) and X-ray film exposure.

A p44/42 MAP kinase assay kit (Cell Signaling Technology) was used to measure phospho-Elk1 molecules as described previously [9,21,22]. An ELISA kit for Trans ${ }^{\mathrm{AM}}{ }^{\circledR}$ AP-1 was obtained from Active Motif (Carlsbad, CA, USA). Equal volumes of conditioned media were obtained from cells and the protein levels in the culture supernatants following BFT stimulation were measured using commercially available ELISA kits for soluble MMP-7 (Invitrogen, Carlsbad, CA, USA) and soluble syndecan-2 (LifeSpan Biosciences Inc., Seattle, WA, USA). Each assay was performed according to the relevant manufacturer instructions.

\subsection{Statistical Analyses}

Data are indicated as the mean \pm SEM and the Mann-Whitney t-test was used for the statistical analyses. A $p$ value less than 0.05 was considered statistically significant.

Author Contributions: Conceptualization, J.M.K.; methodology, J.I.J.; software, J.I.J.; validation, J.I.J. and J.M.K.; formal analysis, J.I.J., K.H.L. and J.M.K.; investigation, J.M.K.; resources, J.M.K. and K.H.L.; data curation, J.I.J., and J.M.K.; writing—original draft preparation, J.M.K.; writing-review and editing, J.M.K.; visualization, J.I.J.; supervision, J.M.K.; project administration, J.M.K.; funding acquisition, J.M.K. and K.H.L. All authors have read and agreed to the published version of the manuscript.

Funding: This research was supported by the Basic Science Research Program through the National Research Foundation of Korea (NRF) funded by the Ministry of Education, Science and Technology (MEST) (NRF-2021R1F1A1045550), Republic of Korea.

Institutional Review Board Statement: Not applicable.

Informed Consent Statement: Not applicable.

Conflicts of Interest: The authors have no conflict of interest to declare.

\section{References}

1. Sears, C.L.; Geis, A.L.; Housseau, F. Bacteroides fragilis subverts mucosal biology: From symbiont to colon carcinogenesis. J. Clin. Investig. 2014, 124, 4166-4172. [CrossRef]

2. Sears, C.L. Enterotoxigenic Bacteroides fragilis: A rogue among symbiotes. Clin. Microbiol. Rev. 2009, 22, 349-369. [CrossRef]

3. Sears, C.L. The toxins of Bacteroides fragilis. Toxicon 2001, 39, 1737-1746. [CrossRef]

4. Jang, B.; Jung, H.; Chung, H.; Moon, B.I.; Oh, E.S. Syndecan-2 enhances E-cadherin shedding and fibroblast-like morphological changes by inducing MMP-7 expression in colon cancer cells. Biochem. Biophys. Res. Commun. 2016, 12, 47-53. [CrossRef]

5. Kim, J.M.; Jung, H.Y.; Lee, J.Y.; Youn, J.; Lee, C.H.; Kim, K.H. Mitogen-activated protein kinase and activator protein-1 dependent signals are essential for Bacteroides fragilis enterotoxin-induced enteritis. Eur. J. Immunol. 2005, 35, 2648-2657. [CrossRef] [PubMed]

6. Wu, S.; Lim, K.C.; Huang, J.; Saidi, R.F.; Sears, C.L. Bacteroides fragilis enterotoxin cleaves the zonula adherens protein, E-cadherin. Proc. Natl. Acad. Sci. USA 1998, 95, 14979-14984. [CrossRef] [PubMed]

7. Zhou, D.; Tian, Y.; Sun, L.; Zhou, L.; Xiao, L.; Tan, R.J.; Tian, J.; Fu, H.; Hou, F.F.; Liu, Y. Matrix metalloproteinase-7 is a urinary biomarker and pathogenic mediator of kidney fibrosis. J. Am. Soc. Nephrol. 2017, 28, 598-611. [CrossRef] 
8. Brabletz, T.; Jung, A.; Dag, S.; Hlubek, F.; Kirchner, T. $\beta$-Catenin Regulates the Expression of the Matrix Metalloproteinase-7 in Human Colorectal Cancer. Am. J. Pathol. 1999, 155, 1033-1038. [CrossRef]

9. Jeon, J.I.; Ko, S.H.; Kim, J.M. Intestinal Epithelial Cells Exposed to Bacteroides fragilis Enterotoxin Regulate NF- $\mathrm{kB}$ Activation and Inflammatory Responses through $\beta$-Catenin Expression. Infect. Immun. 2019, 87, e00312-19. [CrossRef]

10. Kelppe, J.; Thorén, H.; Haglund, C.; Sorsa, T.; Hagström, J. MMP-7, -8, -9, E-cadherin, and beta-catenin expression in 34 ameloblastoma cases. Clin. Exp. Dent. Res. 2021, 7, 63-69. [CrossRef]

11. Löffek, S.; Schilling, O.; Franzke, C.W. Biological role of matrix metalloproteinases: A critical balance. Eur. Resp. J. 2011, 38, 191-208. [CrossRef] [PubMed]

12. Pittayapruek, P.; Meephansan, J.; Prapapan, O.; Komine, M.; Ohtsuki, M. Role of Matrix Metalloproteinases in Photoaging and Photocarcinogenesis. Int. J. Mol. Sci. 2016, 17, 868. [CrossRef] [PubMed]

13. Garalla, H.M.; Lertkowit, N.; Tiszlavicz, L.; Reisz, Z.; Holmberg, C.; Beynon, R.; Simpson, D.; Varga, A.; Kumar, J.D.; Dodd, S.; et al. Matrix metalloproteinase (MMP)-7 in Barrett's esophagus and esophageal adenocarcinoma: Expression, metabolism, and functional significance. Physiol. Rep. 2018, 6, e13683. [CrossRef] [PubMed]

14. Liao, H.Y.; Da, C.M.; Liao, B.; Zhang, H.H. Roles of matrix metalloproteinase-7 (MMP-7) in cancer. Clin. Biochem. 2021, 92, 9-18. [CrossRef]

15. Ho, B.Y.; Wu, Y.M.; Chang, K.J.; Pan, T.M. Dimerumic acid inhibits SW620 cell invasion by attenuating $\mathrm{H}_{2} \mathrm{O}_{2}-\mathrm{mediated} \mathrm{MMP-7}^{-}$ expression via JNK/C-Jun and ERK/C-Fos activation in an AP-1-dependent manner. Int. J. Biol. Sci. 2011, 7, 869-880. [CrossRef] [PubMed]

16. Kwon, M.J.; Hong, E.; Choi, Y.; Kang, D.H.; Oh, E.S. Interleukin-1 $\alpha$ promotes extracellular shedding of syndecan-2 via induction of matrix metalloproteinase-7 expression. Biochem. Biophys. Res. Commun. 2014, 446, 487-492. [CrossRef]

17. Lee, S.H.; Song, K.S.; Sohn, D.H.; Seo, G.S. Polyozellin blocks tumor necrosis factor a-induced interleukin 8 and matrix metalloproteinase 7 production in the human intestinal epithelial cell line HT-29. Arch. Pharm. Res. 2011, 34, 91-97. [CrossRef]

18. Shi, M.; Liu, D.; Duan, H.; Han, C.; Wei, B.; Qian, L.; Chen, C.; Guo, L.; Hu, M.; Yu, M.; et al. Catecholamine up-regulates MMP-7 expression by activating AP-1 and STAT3 in gastric cancer. Mol. Cancer 2010, 9, 269. [CrossRef]

19. Kim, J.M.; Oh, Y.K.; Kim, Y.J.; Oh, H.B.; Cho, Y.J. Polarized secretion of CXC chemokines by human intestinal epithelial cells in response to Bacteroides fragilis enterotoxin: NF- $\mathrm{kB}$ plays a major role in the regulation of IL-8 expression. Clin. Exp. Immunol. 2001, 123, 421-427. [CrossRef] [PubMed]

20. Kim, J.M.; Lee, J.Y.; Youn, Y.M.; Oh, Y.K.; Kang, J.S.; Kim, Y.J.; Kim, K.H. Bacteroides fragilis enterotoxin induces cyclooxygenase-2 and fluid secretion in intestinal epithelial cells through NF-kappaB activation. Eur. J. Immunol. 2006, 2446-2456. [CrossRef]

21. Ko, S.H.; Jeon, J.I.; Woo, H.A.; Kim, J.M. Bacteroides fragilis enterotoxin upregulates heme oxygenase-1 in dendritic cells via reactive oxygen species-, mitogen-activated protein kinase-, and Nrf2-dependent pathway. World J. Gastroenterol. 2020, 26, 291-306. [CrossRef]

22. Jeon, J.I.; Choi, J.H.; Lee, K.H.; Kim, J.M. Bacteroides fragilis Enterotoxin Induces Sulfiredoxin-1 Expression in Intestinal Epithelial Cell Lines Through a Mitogen-Activated Protein Kinases- and Nrf2-Dependent Pathway, Leading to the Suppression of Apoptosis. Int. J. Mol. Sci. 2020, 21, 5383. [CrossRef] [PubMed]

23. Ko, S.H.; Rho, D.J.; Jeon, J.I.; Kim, Y.J.; Woo, H.A.; Lee, Y.K.; Kim, J.M. Bacteroides fragilis Enterotoxin Upregulates Heme Oxygenase-1 in Intestinal Epithelial Cells via a Mitogen-Activated Protein Kinase- and NF-kappaB-Dependent Pathway, Leading to Modulation of Apoptosis. Infect. Immun. 2016, 84, 2541-2554. [CrossRef]

24. Roh, H.C.; Yoo, D.Y.; Ko, S.H.; Kim, Y.J.; Kim, J.M. Bacteroides fragilis enterotoxin upregulates intercellular adhesion molecule-1 in endothelial cells via an aldose reductase-, MAPK-, and NF-kappaB-dependent pathway, leading to monocyte adhesion to endothelial cells. J. Immunol. 2011, 187, 1931-1941. [CrossRef]

25. Choi, S.; Kim, J.Y.; Park, J.H.; Lee, S.T.; Han, I.O.; Oh, E.S. The matrix metalloproteinase-7 regulates the extracellular shedding of syndecan-2 from colon cancer cells. Biochem. Biophys. Res. Commun. 2012, 417, 1260-1264. [CrossRef] [PubMed]

26. Grindel, B.J.; Martinez, J.R.; Pennington, C.L.; Muldoon, M.; Stave, J.; Chung, L.W.; Farach-Carson, M.C. Matrilysin/matrix metalloproteinase-7 (MMP7) cleavage of perlecan/HSPG2 creates a molecular switch to alter prostate cancer cell behavior. Matrix. Biol. 2014, 36, 64-76. [CrossRef] [PubMed]

27. Taniguchi, M.; Matsuura, K.; Nakamura, R.; Kojima, A.; Konishi, M.; Akizawa, T. MMP-7 cleaves amyloid beta fragment peptides and copper ion inhibits the degradation. Biometals 2017, 30, 797-807. [CrossRef]

28. Bebb, J.R.; Letley, D.P.; Thomas, R.J.; Aviles, F.; Collins, H.M.; Watson, S.A.; Hand, N.M.; Zaitoun, A.; Atherton, J.C. Helicobacter pylori upregulates matrilysin (MMP-7) in epithelial cells in vivo and in vitro in a Cag dependent manner. Gut 2003, 52, 1408-1413. [CrossRef]

29. Chang, M.C.; Chen, C.A.; Chen, P.J.; Chiang, Y.C.; Chen, Y.L.; Mao, T.L.; Lin, H.W.; Lin Chiang, W.H.; Cheng, W.F. Mesothelin enhances invasion of ovarian cancer by inducing MMP-7 through MAPK/ERK and JNK pathways. Biochem. J. 2012, 442, 293-302. [CrossRef]

30. Yin, Y.; Zhang, F.; Zheng, Z.; Xiao, Z.; Yang, Q.; Gong, N.; Zhou, J.; Zuo, D.; Ai, J. MMP-7 affects peritoneal ultrafiltration associated with elevated aquaporin-1 expression via MAPK/ERK pathway in peritoneal mesothelial cells. J. Cell Mol. Med. 2021, 25, 6887-6898. [CrossRef] [PubMed]

31. Wu, S.; Rhee, K.J.; Zhang, M.; Franco, A.; Sears, C.L. Bacteroides fragilis toxin stimulates intestinal epithelial cell shedding and gamma-secretase-dependent E-cadherin cleavage. J. Cell Sci. 2007, 120, 1944-1952. [CrossRef] [PubMed] 
32. Rossetti, C.A.; Drake, K.L.; Siddavatam, P.; Lawhon, S.D.; Nunes, J.E.; Gull, T.; Khare, S.; Everts, R.E.; Lewin, H.A.; Adams, L.G. Systems biology analysis of Brucella infected Peyer's patch reveals rapid invasion with modest transient perturbations of the host transcriptome. PLoS ONE 2013, 8, e81719. [CrossRef]

33. Haynes, A.; Ruda, F.; Oliver, J.; Hamood, A.N.; Griswold, J.A.; Park, P.W.; Rumbaugh, K.P. Syndecan 1 shedding contributes to Pseudomonas aeruginosa sepsis. Infect. Immun. 2005, 73, 7914-7921. [CrossRef] [PubMed]

34. Henry-Stanley, M.J.; Hess, D.J.; Erlandsen, S.L.; Wells, C.L. Ability of the heparan sulfate proteoglycan syndecan-1 to participate in bacterial translocation across the intestinal epithelial barrier. Shock 2005, 24, 571-576. [CrossRef]

35. Freissler, E.; Meyer auf der Heyde, A.; David, G.; Meyer, T.F.; Dehio, C. Syndecan-1 and syndecan- 4 can mediate the invasion of OpaHSPG-expressing Neisseria gonorrhoeae into epithelial cells. Cell Microbiol. 2000, 2, 69-82. [CrossRef]

36. Bobardt, M.D.; Saphire, A.C.; Hung, H.C.; Yu, X.; Van der Schueren, B.; Zhang, Z.; David, G.; Gallay, P.A. Syndecan captures, protects, and transmits HIV to T lymphocytes. Immunity 2003, 18, 27-39. [CrossRef]

37. Han, J.; Shi, Y.; Willis, G.; Imani, J.; Kwon, M.Y.; Li, G.; Ayaub, E.; Ghanta, S.; Ng, J.; Hwang, N.; et al. Mesenchymal stromal cell-derived syndecan-2 regulates the immune response during sepsis to foster bacterial clearance and resolution of inflammation. FEBS J. 2021. [CrossRef]

38. Jang, B.; Yun, J.H.; Choi, S.; Park, J.; Shin, D.H.; Lee, S.T.; Lee, W.; Oh, E.S. Tyrosine 51 residue of the syndecan-2 extracellular domain is involved in the interaction with and activation of pro-matrix metalloproteinase-7. Sci. Rep. 2019, 9, 10625. [CrossRef] [PubMed]

39. Ko, S.H.; Jeon, J.I.; Myung, H.S.; Kim, Y.J.; Kim, J.M. Bacteroides fragilis Enterotoxin Induces Formation of Autophagosomes in Endothelial Cells but Interferes with Fusion with Lysosomes for Complete Autophagic Flux through a Mitogen-Activated Protein Kinase-, AP-1-, and C/EBP Homologous Protein-Dependent Pathway. Infect. Immun. 2017, 85, e00420-17. [PubMed] 